\section{Enhancing Savonius Turbine Self-starting Capability by Installing a Circular Cylinder in Front of Returning Turbine Blade}

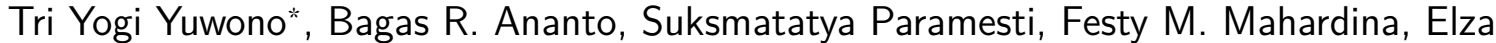 \\ Lisdarina, Vega N. Arif, Dionisius Jeremia, Michael L. Budihartono, Afiyah Shuhufam \\ Department of Mechanical Engineering, Institut Teknologi Sepuluh Nopember, Surabaya 60111, Indonesia \\ Received: 1 October 2020, Revised: 3 February 2021, Accepted: 10 February 2021
}

\begin{abstract}
The effect of installing a circular cylinder in front of the returning turbine blade in enhancing the self-starting capability of the Savonius wind turbine has been studied experimentally by measuring the static torque of the turbine at the angular positions of the blades. The circular cylinder with a diameter relative to the blade diameter $d / D=0.5$ is installed at a distance corresponding to the blade diameter in front of the returning turbine blade which is varied by $1.2 \leq S / D \leq 2.6$. The experiments were carried out for Reynolds number $(R e)=74,000,136,000$, and 175,000. The results showed that the presence of a circular cylinder installed in front of the returning turbine blade at a distance of 1.4 $\leq S / D \leq 1.8$ was able to achieve the self-starting capability of the Savonius wind turbine as indicated by the positive values of the turbine static torque coefficient at all blade angular positions. The highest performance of the Savonius turbine self-starting capability is obtained at the circular cylinder position $S / D=1.6$ for the Reynolds number $(R e)=136,000$, and 175,000 .
\end{abstract}

Keywords: Savonius turbine, self-starting, circular cylinder, static torque coefficient, returning turbine blade

\section{Introduction}

Efforts to use wind power and continue to increase it as a renewable energy source are a smart decision and a reflection of environmental friendliness. Meanwhile, the exploration of fossil energy sources which we all know is getting depleted, there will be many difficulties, and besides that, it threatens environmental sustainability. The Savonius wind turbine, a simple turbine, cheap and easy to manufacture, is the right candidate to answer the efforts to increase wind energy utilisation above. Savonius turbines, which are generally shaped like the letter "S", have a convex blade or returning turbine blade and concave blade or is called advancing blade. This turbine works based on the different drag forces that occur in the returning and advancing blades. Viewing from the wind direction, a concave advancing blade has a higher drag coefficient than a convex returning blade. The drag force acting on the advancing blade is higher than acting on the returning blade, providing positive torque and ultimately generating turbine power.

Since the performance of the Savonius turbine is the lowest compared to other turbines, many studies have been conducted to improve the performance of the Savonius turbine. In the last five years, there have been researchers such as; [1, -8$]$, where they did a lot of study on the shape and the thickness of the turbine blades. Meanwhile, the authors [9.-12] concentrated more on overlap- ping the two blades or varying the number of blades, or the authors [13] have studied the effect of end plates, a number of turbine stages as well as various aspect ratios and overlap ratios of turbines. Furthermore, the authors [14] have installed a flat plate in front of the returning blade to improve the performance of the Savonius turbine. The purpose of installing a flat plate in front of the returning turbine blade is to eliminate the drag forces acting on the returning blade. They have claimed that the Savonius turbine equipped with the flat plate has a higher power coefficient than conventional Savonius turbine. Likewise, the authors [15], by installing a retaining plate in front of the returning blade, have succeeded in increasing the power of the conventional Savonius turbine by $27.3 \%$ higher. The influence of the flat plate width placed on the upstream of the returning blade was investigated by [16] and [17] numerically and experimentally, respectively. They have claimed that, in this configuration, the plate width and the Reynolds number have an important role to play in improving turbine performance. Different from other researchers, the authors [18] and [19] have used a circular cylinder to reduce the drag forces acting on the returning blade and to increase the forces acting on the advancing blade, respectively. They have stated that the power coefficient of turbine increase by $41 \%$ [18] and by $17.3 \%$ [19], respectively. Then, their compatriots from the Laboratory of Fluid Mechanics and Fluid Machinery, Department of Mechanical

*Corresponding author. Email: triyogi@me.its.ac.id 
Engineering, Institut Teknologi Sepuluh Nopember, the authors [20] have used an I-65 type cylinder installed in front of the returning turbine blade. They have found a power coefficient increase of about $23.6 \%$ compared to the conventional turbine. Recently, the authors [21] have published the use of circular cylinder installed in front of the returning turbine blade to improve the performance of the Savonius turbine. They have claimed an increase of about $12.2 \%$ of the turbine power coefficient, for the ratio of cylinder diameter to turbine rotor diameter $d / D=0.54$ and operated at the Reynolds number $(R e)=99,000$.

For a different purpose, to reduce the drag force acting on a circular cylinder, the authors [22] have used small circular cylinder or rod that is mounted on the upstream of a larger circular cylinder. They have ensured that the existence of a rod at the upstream of the larger circular cylinder produces a $37 \%$ reduction in total drag compared to the larger circular cylinder in the single configuration. The authors [23] have also confirmed that the presence of the rod mounted in front of the larger circular cylinder can cause the reduction of the drag forces of the larger circular cylinder behind it. The authors [24] have compared the use of small round cylinders and I-type small cylinders with varying cutting angles as a disturbance mounted in front of a larger circular cylinder. They have proven that the I-type cylinder with a cutting angle $\theta_{s}=65^{\circ}$ is the most effective in reducing the drag force acting on the larger circular cylinder behind it, among the small cylinders tested in their study. The drag force reduction obtained is about $52 \%$ of the single cylinder.

The above studies inspire this study to use a circular cylinder installed in front of the returning turbine blade to improve the Savonius turbine performance. The goal of this study is to enhance the self-starting capability of the Savonius wind turbine by placing a circular cylinder in front of the returning turbine blade. At a certain wind direction concentration to initiate the rotation of the Savonius turbine with a certain blade angle position, it is possible that the drag force acting on the returning blade is higher than that of the advancing blade. In this condition, the turbine rotation tends to reverse direction or gives negative torque. It indicates that the turbine is losing its self-starting capability. This loss of self-starting capability can be reduced or even eliminated as much as possible by reducing the drag force acting on the returning turbine blade at any angular position of the blade. The interaction between the circular cylinder and the returning turbine blade behind it is expected to cause at least two flow phenomena around the returning blade, i.e.: (i) the pressure between the circular cylinder and the returning blade decrease while the pressure behind the returning blade increases. It is as evidenced by [22], [23] and also [24] for the downstream circular cylinder case. As a result, the pressure drag acting on the returning blade is reduced, (ii) the shear layer detached from the circular cylinder will attach to the returning blade surface. It disturbs the boundary layer on the surface of the returning blade and triggers an accelerated transformation of the laminar boundary layer into a turbulent boundary layer, as confirmed by [21]. It will delay the separation point, and as a result, the wake formed behind the returning blade becomes narrower. It causes the drag force acting on the returning blade to decrease. Reducing the drag acting on the returning blade is the aim of this study, where the reduction of the returning blade drag is expected to make it easier for the turbine to start rotation which is called the self-starting capability of the turbine. The self-starting capability of the turbine is determined by measuring the static torque of the turbine to define the static torque coefficient $\left(C_{T_{s}}\right)$. It is a function of the angular position of the blade, for the wind speed is varied by $3.8 \mathrm{~m} / \mathrm{s}, 7$ $\mathrm{m} / \mathrm{s}$, and $9 \mathrm{~m} / \mathrm{s}$, corresponding to the Reynolds number $(R e)=74,000,136,000$, and 175,000, respectively. The circular cylinder is mounted at a distance relative to the blade diameter of $1.2 \leq S / D \leq 2.6$.

\section{Experimental Set-up}

A schematic of the experimental set-up is presented in Figure 1. The experiment was carried out in the open air to simulate the actual conditions, but certainly not affected by outside winds. As a wind energy source, an axial fan (type CKE SPV-18) with a capacity of $125 \mathrm{~m}^{3} / \mathrm{min}$ is installed at a distance of $3200 \mathrm{~mm}$ in front of the turbine. A honeycomb is placed at $800 \mathrm{~mm}$ from the axial fan to eliminate the effect of swirl flow from the fan and maintain the uniformity of the flow.

The turbine blades are made of plastic pipe, Polyvinyl chloride (PVC), with a diameter $(D)=167 \mathrm{~mm}$, a height $(H)=298 \mathrm{~mm}$ and a thickness $(t)=3 \mathrm{~mm}$. The turbine used in this study was different from that used by [20], where the turbine shaft which has a diameter of $(b)=$ $19 \mathrm{~mm}$ is solid, not hollow, as used by [20]. So, the turbine used is relatively heavier and has a higher inertia moment. As a result, it is relatively difficult to rotate or requires more forces to start rotating, but it is even suitable for self-starting turbine tests. The turbine is equipped with end-plates with a $\left(D_{o}\right)=320 \mathrm{~mm}$ diameter. The circular cylinder is also made of PVC with a height $(h)=500 \mathrm{~mm}$ and a diameter of $(d)=83 \mathrm{~mm}$ which gives a $d / D$ ratio of about 0.5 . The distance of placing the circular cylinder in front of the returning blade varies, where the ratio of the distance to the diameter of the blade is $1.2 \leq S / D \leq 2.6$.

Figure $2 \mathrm{a}$ shows a schematic placement of a circular cylinder in front of the returning turbine blade, where the distance $S$ is measured between the circular cylinder axis and the turbine axis. The freestream velocity generated by the fan is varied of $U=3.8 \mathrm{~m} / \mathrm{s}, 7 \mathrm{~m} / \mathrm{s}$, and $9 \mathrm{~m} / \mathrm{s}$, which are correspond to the Reynolds number (Re) of 74,000 , 136,000 and 175,000 , respectively. The free stream velocity $(U)$ is measured at a position around 4D upstream of the turbine using the Omega HHF14 type anemometer which has a measurement range of 1.5 to $35 \mathrm{~m} / \mathrm{s}$ and an accuracy of $\pm 1 \%$. 


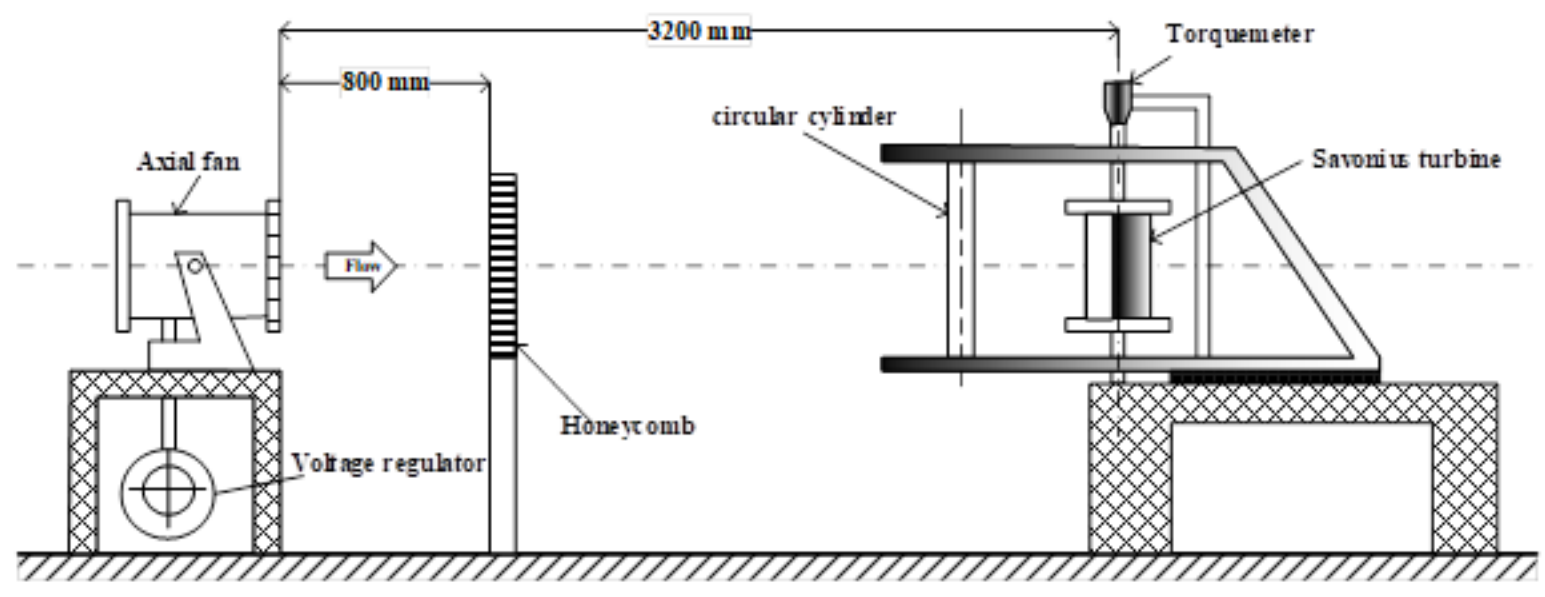

Figure 1. Experimental set-up

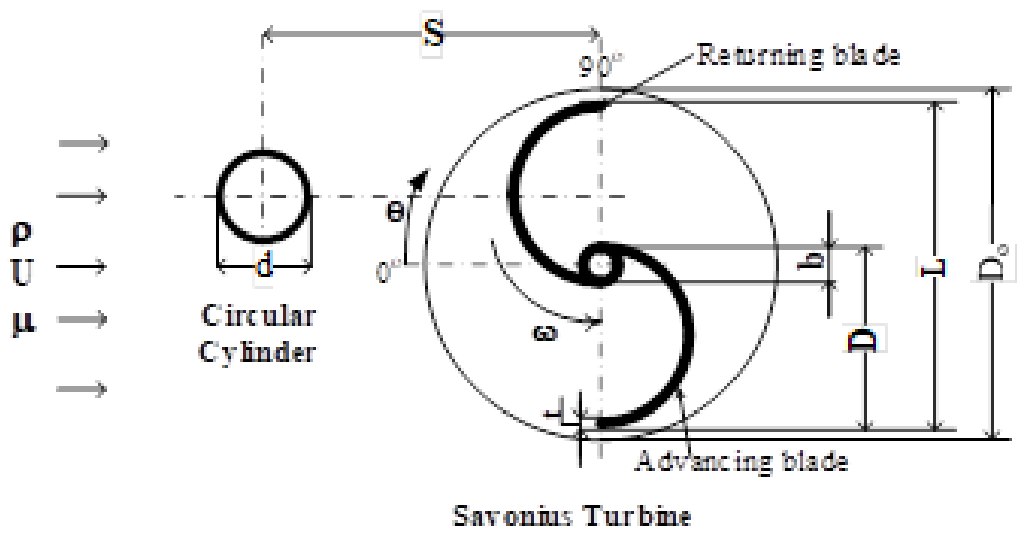

(a) Schematic of placing a circular cylinder in front of the returning turbine blade

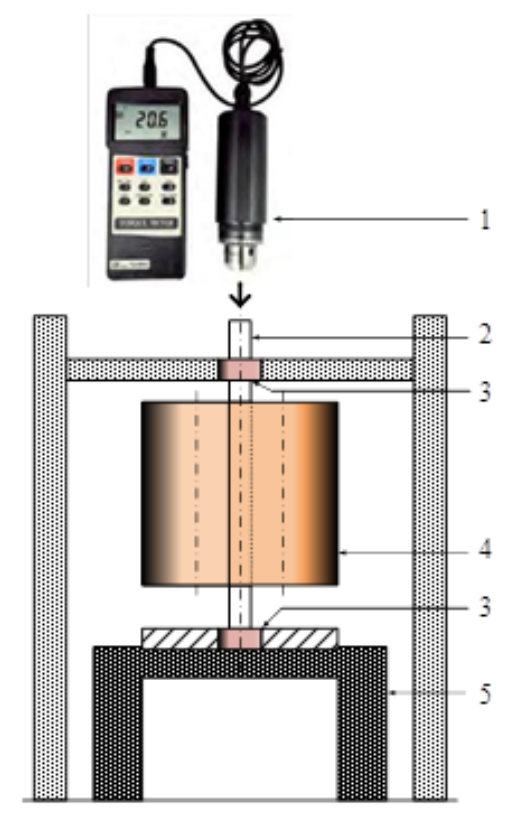

(b) Schematic of static torque measurement (1. Torque Meter, 2. Shaft, 3. Bearing, 4. Turbine, 5. Test Bench)

Figure 2. Savonius turbine

In this experimental, the static torque of the turbine is measured using a torque meter of Lutron TQ-8800 type having a range of measurement of 0 to $147.1 \mathrm{~N} . \mathrm{cm}$ and an accuracy of $0.1 \mathrm{~N} . \mathrm{cm}$. This torque meter is plugged into the turbine shaft, as shown in the schematic of static torque measurement, Figure 2b, Static turbine torque measurement is done by first placing the turbine blade at the desired angle position, and a torque meter plugged on the shaft. Then the air is flowed at the desired velocity, and the turbine is maintain stopped (not rotating) so that the torque reading on the torque meter is expressed as static torque of the turbine at the appropriate blade angle position. This turbine static torque measurement is repeated for every $10^{\circ}$ blade angle position from $0^{\circ}$ to $360^{\circ}$.

In this research, there are two non-dimensional parameters presented to define the self-starting capability, such as; the Reynolds number $(R e)$ and the static torque coefficient $\left(C_{T_{s}}\right)$. The Reynolds is formulated based on the free stream velocity $(U)$ and the characteristic length $(L)$, with $(\mu)$ and $(\rho)$ are the air viscosity and the air density, respectively, so $(R e)$ is presented as:

$$
R e=\frac{\rho U L}{\mu}
$$


where the characteristic length $(L)$ is calculated by $L=$ $2 D-b-2 t$, with $D, b$ and $t$ are the blade diameter, the shaft diameter and the blade thickness, respectively.

Based on the static torque measured $\left(T_{s}\right)$, so the static torque coefficient can be determined as follow:

$$
C_{T_{s}}=\frac{4 T_{s}}{\rho U^{2} H L^{2}}
$$

where $H$ is the height of the turbine blade.

\section{Results and Discussion}

The evolution of the static torque coefficient of the turbine $\left(C_{T_{s}}\right)$ without a circular cylinder as a function of the blade angle position, for the Reynolds number variations of $74,000,136,000$, and 175,000 , is presented in Figure 3. The Figure 3 shows, first; the trend is the same for all three graphs, where the maximum static torque is obtained at a blade angle position of about $30^{\circ}$ and the minimum value at about $150^{\circ}$. Second, there are negative static torque coefficient values for all the Reynolds numbers tested. This negative value means that the drag force acting on the returning blade is higher than that of the advancing blade, causing the turbine to tend to rotate in the reversal direction. It is called the turbine losing self-starting capability.

Figure 3 also shows that the smaller the Reynolds number, the wider the area of negative static torque, or in other words, the wider the area where the turbine does not have the self-starting capability when the Reynolds number gets smaller. The area of the static torque coefficient is negative in the range of the blade angle po- sition $(\theta)$ around; $60^{\circ}<\theta<180^{\circ}, 90^{\circ}<\theta<170^{\circ}$ and $120^{\circ}<\theta<160^{\circ}$ for The Reynolds number $(R e)=$ $74,000,136,000$, and 175,000 , respectively. It is clear that the smaller the Reynolds number means, the smaller the free stream velocity, which means less wind kinetic energy comes to turn the turbine.

Figure 4, 5 and 6 presented the evolution of the static torque coefficient of the turbine with a circular cylinder installed in front of the returning turbine blade at $S / D$ $=1.2,1.4,1.6,1.8,2.0,2.2,2.4,2.6$, for the Reynolds number variations of $74,000,136,000$, and 175,000 , respectively. In general discussion, it is important to note that the presence of circular cylinder in front of the returning blade at any distance and any Reynolds number gives a good tendency to increase the self-starting capability of the Savonius turbine. It is confirmed by the negative values of static torque coefficient which tends to diminish due to the presence of the circular cylinder, at any Reynolds number $(R e)$ and any position of the circular cylinder installed.

Figure 4 shows that at $R e=74,000$ the installation of a circular cylinder at any distance in front of the returning blade still gives a negative value of the static torque coefficient area even though it is narrowing from the original range of $60^{\circ}<\theta<180^{\circ}$, before the circular cylinder installed, become $80^{\circ}<\theta<170^{\circ}$ after installing the circular cylinder. It shows that the turbine still does not have the self-starting capability at this blade angle positions. It is most likely due to a low Reynolds number, which means low wind speeds and also gives low energy, making it difficult for the turbine to start rotating.

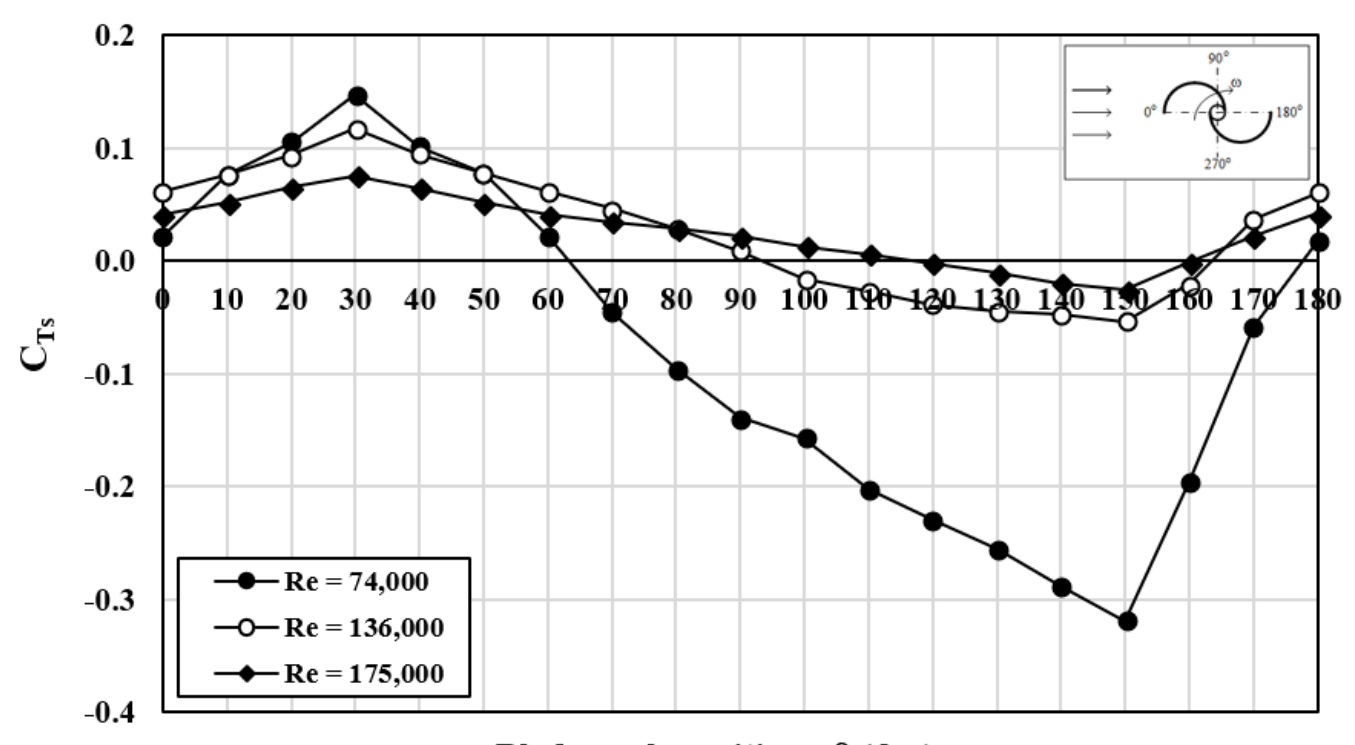

Blade angle position - $\theta(\mathrm{deg})$

Figure 3. Evolution of static torque coefficient as a function of blade angle position for turbine without circular cylinder at varying Reynolds number. 


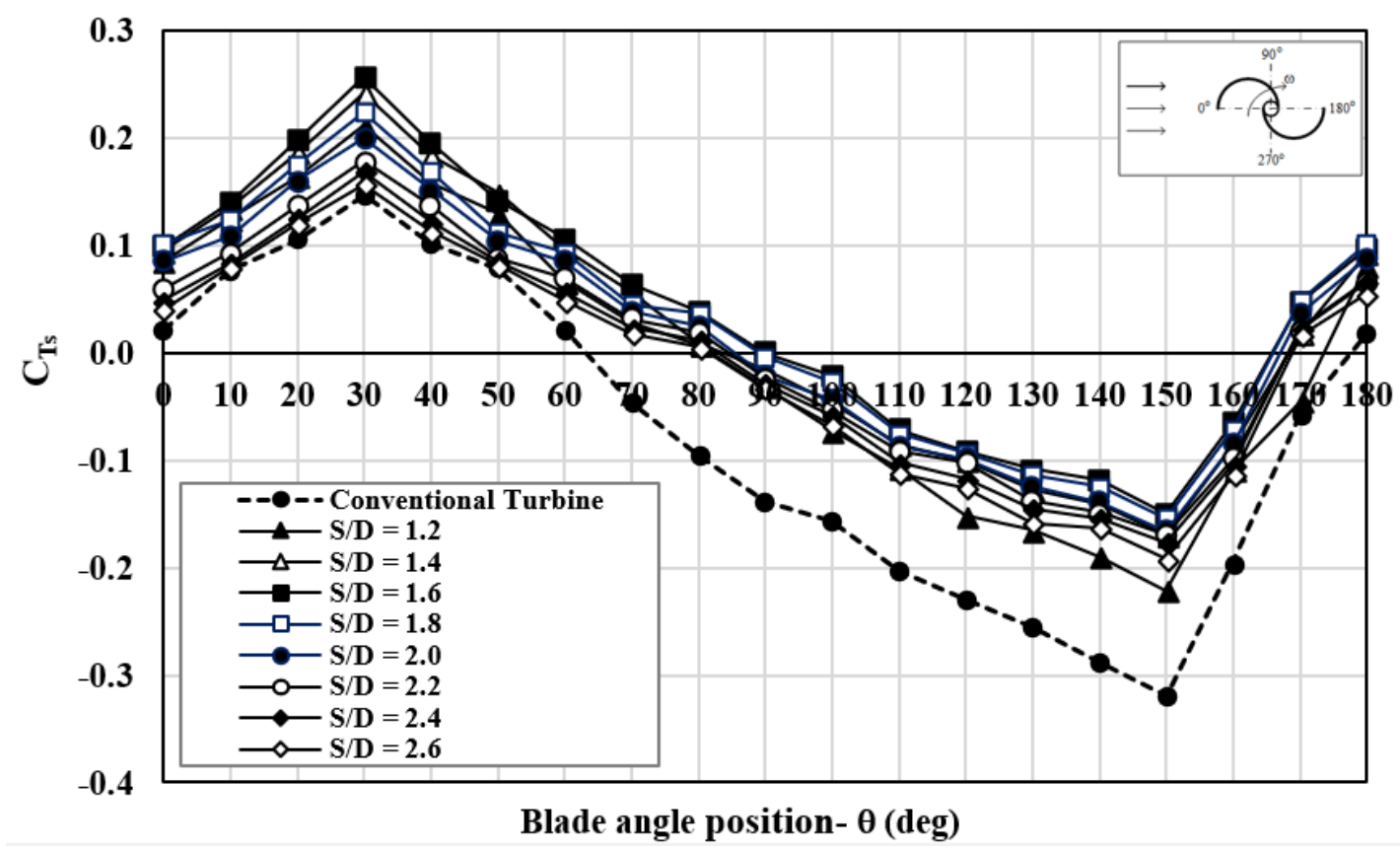

Figure 4. Evolution of the static torque coefficient as a function of the angle position of the turbine blade with the circular cylinder mounted at varying distances $S / D$ for $R e=74,000$.

When the Reynolds number is increased to $R e=$ 136,000 , it can be seen that the installation of a circular cylinder at a distance of $1.4<S / D<1.8$ results in positive static torque coefficient values for all angular positions of the turbine blades, as shown in Figure 5 It means installing a circular cylinder in front of the returning blade at this distance $(1.4<S / D<1.8)$ is very effective in making the turbine have a self-starting capability. Due to the presence of a cylinder in front of the returning blade, it can reduce the drag acting on the returning blade, making it lower than that acting on the advancing blade, resulting in positive torque. This decrease in drag force on the returning blade is due to, firstly, the decrease in pressure on the area between the cylinder and the returning blade and the increase in pressure behind the returning blade, so that the pressure difference between the front and the back of the returning blade decreases and the pressure drag acting on the returning blade also decreases. Secondly, at this $S / D$ distance, the shear layer detaches from the circular cylinder attaches to the surface of the returning blade in the area of the laminar boundary layer, accelerating the transition to the turbulent boundary layer. As a result, the separation point is delayed so that the wake formed behind the returning blade is narrowed and the drag force acting on the returning blade is reduced. These are confirmed by [20].

Unfortunately, when the circular cylinder is installed at a distance of $S / D=1.2$ and $S / D>1.8$, the turbine still has negative static torque coefficient at a range angle of $130^{\circ}<\theta<160^{\circ}$, even though this area is narrower than when without a circular cylinder installed. It seems that the distance of the circular cylinder installed in front of the returning blade has an important role in increasing the self-starting capability of the turbine, where if the circular cylinder is placed too close to the turbine $(S / D=1.2)$, it is not sufficient to increase the self-starting capability of the turbine. This is because, at a distance that is too close, the low-pressure area formed between the cylinder and the returning blade is too narrow so that it does not have an impact on reducing the pressure drag acting on the returning blade.

Besides, it is possible that if the cylinder is too close to the turbine, the shear layer that is detached from the cylinder attached to the surface of the returning blade is already in the turbulent boundary layer area, so that it does not have a significant effect on the flow behaviour in this area, and the separation point is still in its position, and the width of wake formed behind the returning blade is also unchanged. As a result, the drag force acting on the returning blade does not change either. However, this assumption still needs further verification, either through numerical simulations or direct measurements. Likewise, if the cylinder is placed too far from the turbine $(S / D>1.8)$, the presence of the cylinder will not have much impact on the increase in turbine performance, this is because the cylinder and the turbine are like two separate objects that do not affect each other. 


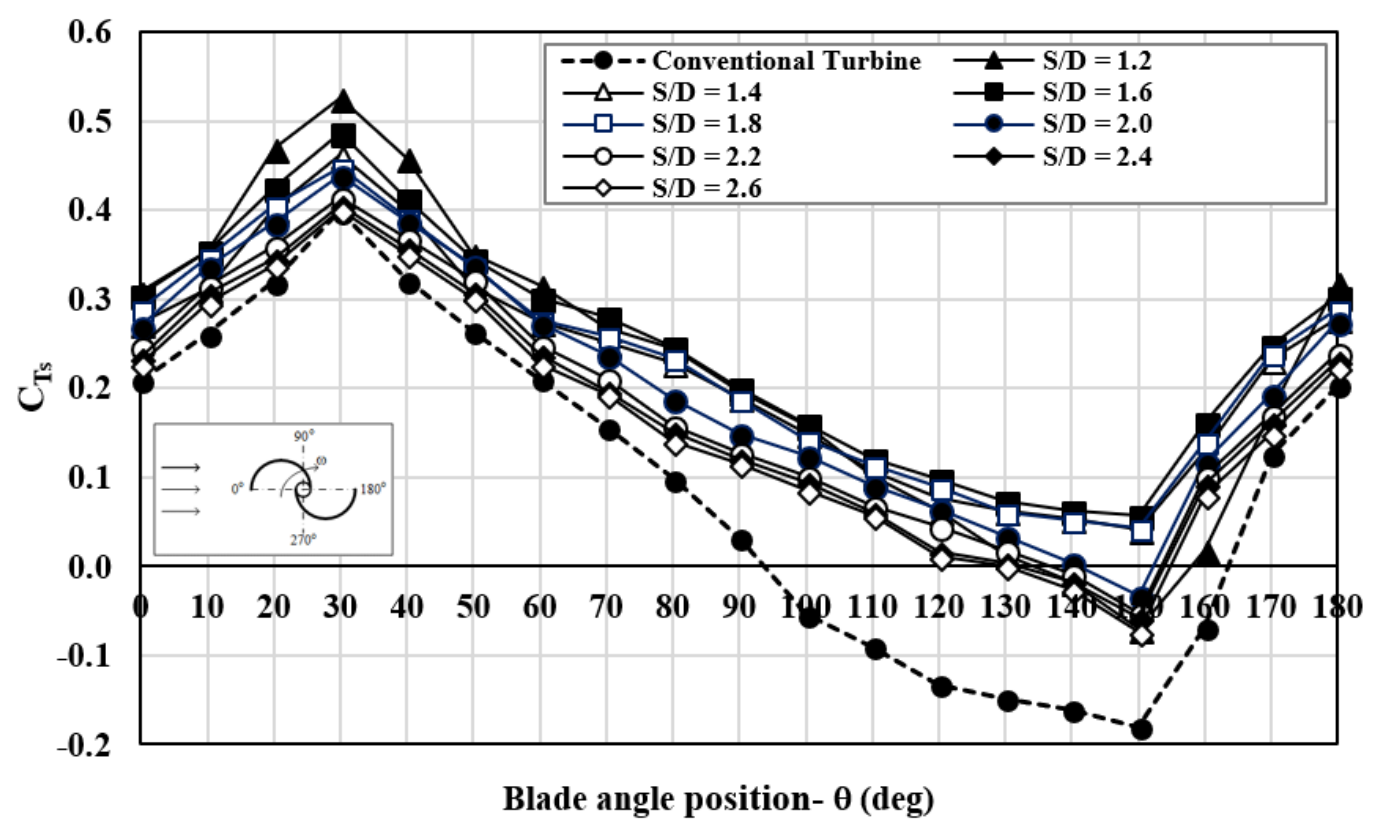

Figure 5. Evolution of the static torque coefficient as a function of the angle position of the turbine blade with the circular cylinder mounted at varying distances $S / D$ for $R e=136,000$.

When the Reynolds number is increased again to Re $=175,000$, as shown in Figure 6, the performance of the turbine is not too different. It even appears that the selfstarting capability of the turbine tested is slightly lower than that for $R e=136,000$. The negative value torque range is slightly wider, which is $130^{\circ}<\theta<160^{\circ}$. Further- more, it is important to note that for $R e=136,000$ and 175,000 the installation of a circular cylinder in front of the returning blade at a distance of $S / D=1.6$ provided the highest performance in enhancing the self-starting capability of the turbine tested.

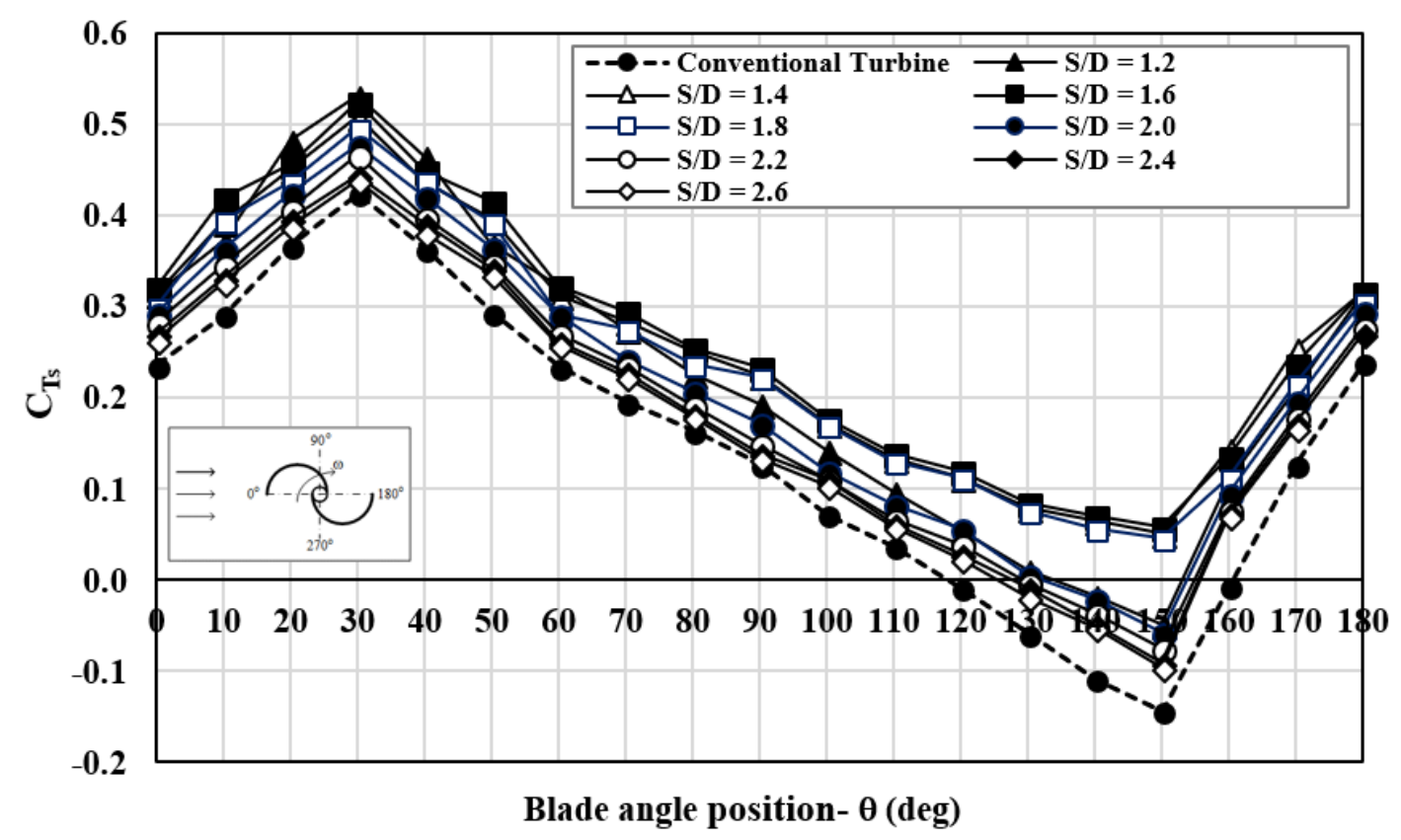

Figure 6. Evolution of the static torque coefficient as a function of the angle position of the turbine blade with the circular cylinder mounted at varying distances $S / D$ for $R e=175,000$. 


\section{Conclusion}

This study is expected to understand experimentally the role of a circular cylinder installed in front of the returning turbine blade to enhance the self-starting capability of the Savonius turbine. A circular cylinder with a diameter relative to the blade diameter $d / D=0.5$ is installed in front of the returning turbine blade at a distance relative to the blade diameter varying of $1.2<S / D<2.6$ for the Reynolds numbers $(R e)=74,000,136,000$, and 175,000 . Based on the results discussed above, it can be concluded as follows:

- The presence of a circular cylinder in front of the returning blade at any distance and any Reynolds number gives a good tendency to increase the selfstarting capability of the Savonius turbine. It is confirmed by the area of negative static torque coefficient which tends to diminish.

- The distance between the cylinder and the returning turbine blade plays an important role in enhancing the self-starting capability of the turbine. When the distance is too close $(S / D<1.4)$ or too far $(S / D>1.8)$ from the returning blade, the installation of circular cylinders in front of the return turbine blade has no significant effect in enhancing the self-starting capability of the turbine. In this study, the placement of a circular cylinder at a relative distance of $1.4<S / D<1.8$ was effective in enhancing the self-starting capability of the turbine. It is indicated by the positive value of the static torque coefficient obtained at all angular positions of the blade.

- The installation of a circular cylinder at a distance of $S / D=1.6$ in front of the returning turbine blade is most effective in enhancing the self-starting capability of the turbine at the Reynolds number $(R e)=$ 136,000 and 175,000 .

\section{Acknowledgements}

The authors thank the Head of the Fluid Mechanics and Fluid Machinery Laboratory of the Department of Mechanical Engineering, Institut Teknologi Sepuluh Nopember, to grant permission to use all experimental facilities. Also, the authors have stated that there is no conflict of interest.

\section{References}

[1] Z. Mao and W. Tian, "Effect of the blade arc angle on the performance of a Savonius wind turbine," Advances in Mechanical Engineering, vol. 7, no. 5, pp. 1-10, 2015.

[2] A. Kumar and R. Saini, "Performance analysis of a Savonius hydrokinetic turbine having twisted blades," Renewable Energy, vol. 108, pp. 502-522, 2017.
[3] C. Chan, H. Bai, and D. He, "Blade shape optimization of the Savonius wind turbine using a genetic algorithm," Applied Energy, vol. 213, pp. 148-157, 2018.

[4] W. Tian, Z. Mao, B. Zhang, and Y. Li, "Shape optimization of a Savonius wind rotor with different convex and concave sides," Renewable Energy, vol. 117, pp. 287-299, 2018.

[5] E. Kerikous and D. Thévenin, "Optimal shape of thick blades for a hydraulic Savonius turbine," Renewable Energy, vol. 134, pp. 629-638, 2019.

[6] E. Kerikous and D. Thévenin, "Optimal shape and position of a thick deflector plate in front of a hydraulic Savonius turbine," Energy, vol. 189, p. 116157, 2019.

[7] M. Masdari, M. Tahani, M. H. Naderi, and N. Babayan, "Optimization of airfoil based Savonius wind turbine using coupled discrete vortex method and salp swarm algorithm," Journal of Cleaner Production, vol. 222, pp. 47-56, 2019.

[8] H. A. Hassan Saeed, A. M. Nagib Elmekawy, and S. Z. Kassab, "Numerical study of improving Savonius turbine power coefficient by various blade shapes," Alexandria Engineering Journal, vol. 58, no. 2, pp. 429-441, 2019.

[9] R. E. Sheldahl, B. F. Blackwell, and L. V. Feltz, "Wind tunnel performance data for two- and three-bucket Savonius rotors," Journal of Energy, vol. 2, no. 3, pp. 160-164, 1978.

[10] M. Shaheen, M. El-Sayed, and S. Abdallah, "Numerical study of two-bucket Savonius wind turbine cluster," Journal of Wind Engineering and Industrial Aerodynamics, vol. 137, pp. 78-89, 2015.

[11] M. Basumatary, A. Biswas, and R. Misra, "CFD analysis of an innovative combined lift and drag (CLD) based modified Savonius water turbine," Energy Conversion and Management, vol. 174, pp. 72-87, 2018.

[12] P. K. Talukdar, A. Sardar, V. Kulkarni, and U. K. Saha, "Parametric analysis of model Savonius hydrokinetic turbines through experimental and computational investigations," Energy Conversion and Management, vol. 158, pp. 36-49, 2018.

[13] N. Mahmoud, A. El-Haroun, E. Wahba, and M. Nasef, "An experimental study on improvement of Savonius rotor performance," Alexandria Engineering Journal, vol. 51, no. 1, pp. 19-25, 2012.

[14] B. D. Altan and M. Atılgan, "The use of a curtain design to increase the performance level of a Savonius wind rotors," Renewable Energy, vol. 35, no. 4, pp. 821-829, 2010. 
[15] M. Mohamed, G. Janiga, E. Pap, and D. Thévenin, "Optimization of Savonius turbines using an obstacle shielding the returning blade," Renewable Energy, vol. 35, no. 11, pp. 2618-2626, 2010.

[16] Y. Triyogi, A. Latip, N. P. Putri, M. Ubaidillah, E. N. Mazhilna, C. Ariyanto, U. Andaryani, and A. Fauzi, "Numerical study on the effect of width of single curtain on the performance of Savonius wind turbine," MATEC Web Conf., vol. 154, p. 01110, 2018.

[17] Y. Triyogi, A. Latip, N. P. Putri, M. Ubaidillah, E. N. Mazhilna, C. Ariyanto, U. Andaryani, A. Fauzi, W. A. Widodo, and B. A. Dwiyantoro, "The effect of width of single curtain on the performance of Savonius wind turbine," AIP Conference Proceedings, vol. 1983, no. 1, p. 020023, 2018.

[18] P. A. Setiawan, Y. Triyogi, and W. A. Widodo, "Effect of a circular cylinder in front of advancing blade on the Savonius water turbine by using transient simulation," International Journal of Mechanical and Mechatronics, vol. 19, no. 01, pp. 151-159, 2019.

[19] P. A. Setiawan, Y. Triyogi, W. A. Widodo, E. Julianto, and M. Santoso, "Numerical study of a circular cylinder effect on the vertical axis Savonius water turbine performance at the side of the advancing blade with horizontal distance variations," International Journal of Renewable Energy Research, vol. 9, no. 2, pp. 978985, 2019.
[20] G. Sakti, Y. Triyogi, and W. A. Widodo, "Experimental and numerical investigation of I- $65^{\circ}$ type cylinder effect on the Savonius wind turbine performance," International Journal of Mechanical and Mechatronics Engineering, vol. 19, no. 5, pp. 115-125, 2019.

[21] Y. Triyogi, G. Sakti, F. N. Aulia, and A. C. Wijaya, "Improving the performance of Savonius wind turbine by installation of a circular cylinder upstream of returning turbine blade," Alexandria Engineering Journal, vol. 59, no. 6, pp. 4923-4932, 2020.

[22] T. Tsutsui and T. Igarashi, "Drag reduction of a circular cylinder in an air-stream," Journal of Wind Engineering and Industrial Aerodynamics, vol. 90, no. 4-5, pp. 527-541, 2002.

[23] S.-J. Lee, S.-I. Lee, and C.-W. Park, "Reducing the drag on a circular cylinder by upstream installation of a small control rod," Fluid Dynamics Research, vol. 34, no. 4, pp. 1-18, 2004.

[24] Y. Triyogi, D. Suprayogi, and E. Spirda, "Reducing the drag on a circular cylinder by upstream installation of an I-type bluff body as passive control," Proceedings of the Institution of Mechanical Engineers, Part C: Journal of Mechanical Engineering Science, vol. 223, no. 10, pp. 2291-2296, 2009. 